\title{
EARLINET dust observations vs. BSC-DREAM8b modeled profiles: 12-year-long systematic comparison at Potenza, Italy
}

\author{
L. Mona ${ }^{1}$, N. Papagiannopoulos ${ }^{1}$, S. Basart ${ }^{2}$, J. Baldasano ${ }^{2,3}$, I. Binietoglou ${ }^{1,4}$, C. Cornacchia ${ }^{1}$, and G. Pappalardo ${ }^{1}$ \\ ${ }^{1}$ Istituto di Metodologie per l'Analisi Ambientale (CNR-IMAA), C.da S. Loja, 85050 Tito Scalo, Potenza, Italy \\ ${ }^{2}$ Barcelona Supercomputing Center, Barcelona, Spain \\ ${ }^{3}$ Environmental Modelling Laboratory, Technical University of Catalonia, Barcelona, Spain \\ ${ }^{4}$ National Institute of R\&D for Optoelectronics Romania - INOE, Magurele, Romania
}

Correspondence to: L. Mona (lucia.mona@imaa.cnr.it)

Received: 13 September 2013 - Published in Atmos. Chem. Phys. Discuss.: 2 December 2013

Revised: 2 June 2014 - Accepted: 19 June 2014 - Published: 26 August 2014

\begin{abstract}
In this paper, we report the first systematic comparison of 12-year modeled dust extinction profiles vs. Raman lidar measurements. We use the BSC-DREAM8b model, one of the most widely used dust regional models in the Mediterranean, and Potenza EARLINET lidar profiles for Saharan dust cases, the largest one-site database of dust extinction profiles. A total of 310 dust cases were compared for the May 2000-July 2012 period. The model reconstructs the measured layers well: profiles are correlated within $5 \%$ of significance for $60 \%$ of the cases and the dust layer center of mass as measured by lidar and modeled by BSC-DREAM8b differ on average $0.3 \pm 1.0 \mathrm{~km}$. Events with a dust optical depth lower than 0.1 account for $70 \%$ of uncorrelated profiles. Although there is good agreement in terms of profile shape and the order of magnitude of extinction values, the model overestimates the occurrence of dust layer top above $10 \mathrm{~km}$. Comparison with extinction profiles measured by the Raman lidar shows that BSC-DREAM8b typically underestimates the dust extinction coefficient, in particular below $3 \mathrm{~km}$. Lowest model-observation differences (below $17 \%$ ) correspond to a lidar ratio at $532 \mathrm{~nm}$ and Ångström exponent at $355 / 532 \mathrm{~nm}$ of $60 \pm 13$ and $0.1 \pm 0.6 \mathrm{sr}$, respectively. These are in agreement with values typically observed and modeled for pure desert dust. However, the highest differences (higher than $85 \%$ ) are typically related to greater Ångström values $(0.5 \pm 0.6)$, denoting smaller particles. All these aspects indicate that the level of agreement decreases with an increase in mixing/modification processes.
\end{abstract}

\section{Introduction}

Desert dust is a major component of atmospheric aerosol. Mineral dust particles are originated by wind erosion of the land surface in arid and semiarid regions and can then travel over long distances. Dust particles play an important role in the Earth system, with impacts on climate, meteorology, ecosystems and human health (WMO report, 2011). Dust particles interact directly with the solar incoming and terrestrial outgoing radiation by absorption and scattering (Boucher et al., 2013). A large uncertainty is related to the dust-cloud interactions and resulting effects on the radiation budget (Boucher et al., 2013). Mineral dust also affects ecosystems. Lower acidity in the ocean has been observed in areas affected by the deposition of dust particles (Johnson, 2014). Saharan dust in particular is found to enhance oceanic primary productivity (Gallisai et al., 2012) and to act as a fertilizer for the Amazon rainforest (Lovett, 2010). Finally, due to the many connections with the Earth's systems, mineral dust can also impact the carbon cycle and the atmospheric $\mathrm{CO}_{2}$ (Jickells et al., 2005; Hamza et al., 2011).

Dust particles also affect human health and air quality. Cases of eye infections and diseases such as meningitis and valley fever have been recorded during and after strong dust events in some regions (Griffin, 2007; WHO, 2003; Pérez et al., 2014). Epidemiological studies have identified a link between pollution of airborne particles over Europe and health hazards such as respiratory and cardiovascular diseases (e.g Kwon et al., 2002; Pérez et al., 2009; De Longueville et al., 2013). Poor air quality due to desert dust intrusions is 
observed and documented by many studies (e.g., Querol et al., 2009). Several other economic and social sectors can be affected by the presence of desert dust, including air transport, solar power generation activities, agriculture and the fishing industry.

The vertical distribution of aerosol is of particular importance because it is a combined signature of atmospheric transport patterns, residence time in the atmosphere, and the efficiency of the vertical exchange. Lidar observations have been widely used for investigating atmospheric desert dust (see Mona et al. ,2012a, for a review). The intrusion of desert dust into the planetary boundary layer (PBL) and mixing processes of dust with other aerosol types can be investigated in detail using the vertical profiling capability of lidars (e.g., Muller et al., 2003; Hara et al., 2009; Mona et al., 2012b). Long-range transport of dust can be monitored and tracked by ground-based lidar networks or spaceborne lidars (e.g., Ansmann et al., 2003; Papayannis et al., 2008; Liu et al., 2008; Schuster et al., 2012). Lidar measurements in combination with other techniques are ideal for investigating certain aspects of atmospheric composition, transport and deposition of aerosol (e.g., Ferrare et al., 1998, 2001).

To date, there have been few examples of comparison between ground-based lidar and modeled profiles (e.g., Ferrare et al., 2006). Raw signals from the spaceborne CALIOP (Cloud-Aerosol Lidar with Orthogonal Polarization) lidar (Winker et al., 2009) were used for evaluating the results from a global chemical and transport model (GEOS-Chem) (Generoso et al., 2008; Ford and Heald, 2012). Koffi et al. (2012) evaluated the capability of 12 models to reproduce the vertical distribution of aerosols observed at the global scale by CALIOP. However, CALIOP extinction retrieval requires the inference of a priori extinction-to-backscatter ratio; therefore the comparison is affected by uncertainties. Amiridis et al. (2013) highlighted that these uncertainties were enhanced during dust outbreaks. Based mainly on Raman lidars, EARLINET (European Aerosol Research Lidar Network) (Bosenberg et al., 2003; Pappalardo et al., 2014) represents a reference point for more common backscatter lidars (and ceilometers) and for the first satellite-borne lidar, CALIOP. The Raman lidar technique allows for direct measurement of the aerosol extinction profile and independent measurement of the aerosol backscatter profile. The ratio of these two quantities, namely the lidar ratio (S), is a quantity that (i) does not depend on the amount of aerosol; (ii) depends on intensive aerosol properties such as dimension, chemical composition and refractive index; and (iii) is needed for assumptions necessary for aerosol optical properties retrieval in the case of elastic backscatter lidar measurements.

Specific EARLINET-coordinated observations are addressed to monitor Saharan dust outbreaks. Dust alerts based on operational dust forecasting of different regional models such as SKIRON (Kallos et al., 2006) and BSC-DREAM8b (Pérez et al., 2006a, b; Basart et al., 2012a) are distributed to all EARLINET network stations. The alerts are important for triggering the lidar measurements and collecting a large data set of dust observations.

This paper reports, for the first time, a systematic comparison between lidar and modeled dust profiles in terms of geometrical features and optical properties. For this systematic comparison with modeled dust extinction profile, Potenza EARLINET station has been selected because it presently has the longest-running and widest-ranging database of Saharan dust aerosol optical properties profiles (from 2000 to present). The BSC-DREAM8b dust regional model (Nickovic et al., 2001; Pérez et al., 2006a, b; Basart et al., 2012a) is used for this study. BSC-DREAM8b is operated at the Barcelona Supercomputer Center-Centro Nacional de Supercomputación (BSC-CNS, www.bsc.es) and is one of the most widely used models for dust investigation over Europe (e.g., Papayannis et al., 2008; Amiridis et al., 2009; Basart et al., 2012b; Amiridis et al., 2013; Gobbi et al., 2013).

Data used for this first comparison are introduced in Sect. 2. Section 3 describes the methodology developed for the lidar vs. BSC-DREAM8b dust extinction profiles comparison in terms of layering and optical properties. Results of the systematic comparison are reported in Sect. 4. Finally, conclusions are reported in Sect. 5.

\section{Data used}

\subsection{Potenza EARLINET lidar data}

For this study, profiles of aerosol optical properties, as measured at CNR-IMAA Atmospheric Observatory (CIAO), Potenza, southern Italy ( $40^{\circ} 36^{\prime} \mathrm{N}, 15^{\circ} 44^{\prime} \mathrm{E} ; 760 \mathrm{~m}$ a.s.l.), are considered. Potenza station is particularly interesting for the investigation of Saharan dust because it has collected the greatest amount of observations on Saharan dust particles among the EARLINET sites. This is due to the fact that Potenza has been participating in the network since its beginning (in 2000), and the station is located in the central region of the Mediterranean Basin, one of the areas most affected by Saharan dust plumes within the network (Papayannis et al., 2008). In addition Potenza is an EARLINET core station, due to it being equipped with a multi-wavelength Raman lidar system (Mona et al., 2009).

For the aims of this study, we considered 12 years (from May 2000 to July 2012) of Potenza vertical profiles labeled as desert dust cases within the EARLINET database as of June 2013 (the EARLINET publishing group, 2014). During this period, the Potenza EARLINET lidar (PEARL) followed some upgrades from a single-wavelength Raman system in 2000 to a multi-wavelength Raman system. This advanced system is able to measure three backscatter $(355,532$ and $1064 \mathrm{~nm}$ ) and two extinction ( 355 and $532 \mathrm{~nm}$ ) profiles, as well as the particle linear depolarization ratio at $532 \mathrm{~nm}$ (Mona et al., 2009; Madonna et al., 2011). Simultaneous 
Table 1. Type and number $(\mathrm{N})$ of optical properties profiles labeled as dust cases in the EARLINET database for the Potenza station. Aerosol backscatter at $1064 \mathrm{~nm}$ and aerosol extinction at $532 \mathrm{~nm}$ are available beginning in May 2006 after a major upgrade of the PEARL instrument.

\begin{tabular}{ll}
\hline Parameter & $\mathrm{N}$ \\
\hline Aerosol backscatter at $355 \mathrm{~nm}$ & 352 \\
Aerosol backscatter at $532 \mathrm{~nm}$ & 248 \\
Aerosol backscatter at $1064 \mathrm{~nm}$ & 276 \\
Aerosol extinction at $355 \mathrm{~nm}$ & 158 \\
Aerosol extinction at $532 \mathrm{~nm}$ & 58 \\
\hline
\end{tabular}

measurements of these optical properties are particularly important for aerosol typing (Mona et al., 2012b) and for aerosol microphysical properties retrievals (e.g., Böckmann et al., 2005; Müller, et al., 2004; Osterloh et al., 2009; Veselovskii et al., 2012; Wagner et al., 2013).

Only profiles affected by desert dust particles are considered for evaluating the capability of the BSC-DREAM8b model to reproduce the desert dust particles arriving over Potenza.

The identification of dust-affected cases is performed following the same approach as reported in Mona et al. (2006): (i) identifying layers in the free troposphere, (ii) checking potential desert origin by back-trajectory analysis and (iii) confirming the presence of dust outbreaks with satellite images/data. In addition to the above-mentioned method, the origin of the observed aerosol layers is also investigated using FLEXPART 10-day back-trajectory analysis (Stohl et al., 1998; Stohl and Thomson, 1999) because of their flexibility in arrival time and altitude definition. In doubtful situations, a multi-backward-trajectory approach and knowledge on dustintensive optical properties gained within EARLINET, and especially for the Potenza site (Papayannis et al., 2008; Mona et al., 2006), are used for the identification of dust case.

This advanced approach confirms the dust origin of the aerosol layers analyzed in Mona et al. (2006) in 93\% of the cases. A different or unclear dust origin is found for cases with an integrated backscatter at $532 \mathrm{~nm}$ around $0.00023 \mathrm{sr}^{-1}$, which is about $1 / 10$ of the observed mean values for the desert dust cases over Potenza reported by Mona et al. (2006).

A total number of 310 dust cases were selected for the analysis reported in the following. All optical properties profiles (see Table 1) were used for the model evaluation in terms of the dust layer geometrical properties discussed in Sect. 4.1. Moreover, aerosol extinction and backscatter coefficient profiles at $532 \mathrm{~nm}$ and aerosol extinction profiles at $355 \mathrm{~nm}$ were considered for a quantitative evaluation of BSC-DREAM8b extinction profiles (Sect. 4.2).

\subsection{The BSC-DREAM8b model}

We used modeled extinction profiles from the BSCDREAM8b model operated at BSC-CNS. BSC-DREAM8b provides operational forecasts since May 2009, and is also participating in the northern Africa-Middle EastEurope (NA-ME-E) node of the SDS-WAS program. BSCDREAM8b (Pérez et al., 2006a, b; Basart et al., 2012a) is a regional model designed to simulate and predict the atmospheric cycle of mineral dust aerosol. The BSC-DREAM8b model is embedded into the Eta/NCEP atmospheric model and solves the mass balance equation for dust, taking into account the different processes of the dust cycle (i.e., dust emission, transport and deposition). The initial version of the DREAM model (Nickovic et al., 2001) included the following features: (1) a dust uplifting scheme according to Shao et al. (1993), with addition of a viscous sublayer approach between the surface and the lowest model layer (Janjic, 1994); (2) a simple wet-scavenging (Nickovic et al., 2001) and drydeposition (Giorgi, 1986) scheme; (3) horizontal and vertical advection, turbulent and lateral diffusion (Janjic, 1994); and (4) soil wetness effects on dust production (Fecan et al., 1999). The BSC-DREAM8b model (Pérez et al., 2006a, b) includes an updated dust production scheme based on the arid and semiarid categories of the $1 \mathrm{~km}$ USGS land use data set and source size distribution derived from D'Almeida (1987), and in order to better couple the dust transport over long distances, a more detailed size bin distribution is used, including eight size bins within $0.1-10 \mu \mathrm{m}$ radius range according to Tegen and Lacis (1996) as well as dust-radiative feedbacks.

The BSC-DREAM8b model has been evaluated for longer periods over northern Africa and Europe (e.g., JiménezGuerrero et al., 2008; Basart et al., 2012a, b; Pay et al., 2010, 2012) and against experimental campaigns in source regions during the SAMUM-1 (Haustein et al., 2009) and the Bodélé Dust Experiments (BoDEx; Todd et al., 2008). Furthermore, daily evaluation of BSC-DREAM8b with near-real-time observations is conducted at BSC-CNS. Currently, the daily operational model evaluation includes satellites (MODIS and MSG) and AERONET sun photometers. Some comparisons between lidar and forecast models profiles were performed in terms of aerosol vertical distribution for specific Saharan dust events in the Mediterranean Basin (e.g., Balis et al., 2004; Pérez et al., 2006a, b; Amiridis et al., 2009; Papanastasiou et al., 2010; Mona et al., 2012b; Gobbi et al., 2013).

Modeled aerosol optical depth (AOD) and dust extinction coefficient are related to column mass loading and mass concentration, respectively, by

$$
\begin{aligned}
& \tau(\lambda)=\sum_{k=1}^{8} \tau_{k}(\lambda)=\sum_{k=1}^{8} \frac{3}{4 \rho_{k} r_{k}} M_{k} Q_{\text {ext }}(\lambda)_{k}, \\
& \alpha(\lambda)=\sum_{k=1}^{8} \alpha_{k}(\lambda)=\sum_{k=1}^{8} \frac{3}{4 \rho_{k} r_{k}} C_{k} Q_{\text {ext }}(\lambda)_{k},
\end{aligned}
$$


where for each size bin, $k, \tau_{k}(\lambda)$ is the $\mathrm{AOD} ; \alpha_{k}(\lambda)$ is the extinction coefficient; $\rho_{k}$ is the particle mass density; $r_{k}$ is the effective radius; $\mathrm{M}_{k}$ is the column mass loading; $C_{k}$ is the concentration; and $Q_{\text {ext }}(\lambda)_{k}$ is the extinction efficiency factor, which was calculated using Mie scattering theory. For each size bin $k$ and wavelength $\lambda$, the extinction efficiency was calculated with a Mie algorithm based on the work of Mishchenko et al. (2002). Complex refractive indices are taken from the Global Aerosol Data Set (GADS) (Koepke et al., 1997). Each particle is assumed to be nonhygroscopic, homogeneous (chemical composition of mineral dust is not included) and spherical. This means that dust is considered externally mixed, non-hygroscopic and inert, and no exchange between bins is taken account.

The present analysis includes a dust simulation of BSCDREAM8b for the period from 1 January 2000 to 31 December 2012 with hourly output. The initial state of dust concentration in the model was defined by the $24 \mathrm{~h}$ forecast from the previous-day model run. The NCEP Final Analyses (at $1^{\circ} \times 1^{\circ}$ horizontal resolution) at 00:00 UTC were used as initial conditions and boundary conditions at intervals of $6 \mathrm{~h}$. The model configuration used for the present study includes 24 Eta vertical layers extending up to approximately $15 \mathrm{~km}$ in the vertical. The resolution is set to $1 / 3^{\circ}$ in the horizontal. The domain of simulation covers northern Africa, the Middle East and Europe. It is worth mentioning that re-suspended wind-blown dust and the considered desert dust sources are limited to northern Africa and the Middle East $\left(<35^{\circ} \mathrm{N}\right)$ in the BSC-DREAM8b model.

\section{Methodology}

The 310 Saharan dust cases observed over Potenza are compared with the BSC-DREAM8b extinction vertical profiles (at $550 \mathrm{~nm}$ ) through a quantitative methodology described in the following.

PEARL and BSC-DREAM8b profiles have different spatial and temporal resolutions. All these differences are appropriately considered in our comparison. For the horizontal resolution, PEARL data can be considered as punctual observations, while BSC-DREAM8b reports profiles on a uniform spatial grid (at horizontal resolution of $1 / 3^{\circ} \times 1 / 3^{\circ}$ ). BSCDREAM8b profiles are averaged over points at a distance less than $15-30 \mathrm{~km}$ by the PEARL lidar.

For the vertical resolution, BSC-DREAM8b provides profiles at fixed altitude ranges above sea level, with resolution varying from $314 \mathrm{~m}$ (around $1.5 \mathrm{~km}$ altitude) up to $1461 \mathrm{~m}$ (around $15 \mathrm{~km}$ altitude). The PEARL lidar profiles instead have a typical effective vertical resolution of $60 \mathrm{~m}$ for the aerosol backscatter coefficient and range between 60 and $240 \mathrm{~m}$ for the aerosol extinction coefficient. The high vertical resolution of lidar makes the lidar techniques indeed the most powerful tool for investigating the vertical structure and composition of the atmosphere. In order to evaluate BSC-
DREAM8b's capability to reproduce dust vertical layering and dust optical properties, the original vertical resolution of lidar profiles is degraded to the resolution of the modeled profiles.

Each lidar profile is then compared to the closest BSCDREAM8b profile in time. Considering that the wind speed in the free troposphere is typically between 5 and $20 \mathrm{~m} \mathrm{~s}^{-1}$ over Potenza (according to ECMWF data), this means that we would expect a maximum shift in time of about $1.5 \mathrm{~h}$. This temporal interval is comparable with the temporal resolution of both BSC-DREAM8b $(1 \mathrm{~h})$ and lidar $(0.5-2.5 \mathrm{~h})$ profiles used in the present analysis. However, BSC-DREAM8b provides instantaneous profiles every hour whereas measured lidar profiles are obtained by merging signals over a $0.5-$ $2.5 \mathrm{~h}$ temporal window depending on the aerosol load (longer intervals are needed for improving the signal-to-noise ratio in cases of tenuous aerosol layers). In addition, BSCDREAM8b and lidar profiles are not simultaneous. Taking into account these aspects/limitations (different resolutions and no exact collocation), all comparisons have been performed for each lidar profile also against the average of the BSC-DREAM $8 \mathrm{~b}$ hourly profiles in $\pm 3 \mathrm{~h}$ around the central lidar time.

In order to evaluate BSC-DREAM8b's performance over the central Mediterranean, aerosol layers of a different origin measured in Potenza were removed.

Besides desert dust, different aerosol types could coexist in the atmospheric column either at altitude ranges different from dust or mixed with dust particles. The back-trajectory analysis described in Sect. 2 is essential for identifying these kinds of cases. During the period under investigation, we found about 10 dust cases with the presence of long-rangetransported aerosol different from desert particles at separate altitude ranges. These are cases of air masses coming from North America during forest fires and volcanic plume transported from the Nabro volcano, Eritrea (Sawamura et al., 2012). Cirrus clouds can be frequently observed concurrently to desert dust but at higher altitudes. After these layers are identified in the lidar optical profile, the base and top of the dust layer are forced for each of the 10 cases to exclude altitude ranges with the presence of other aerosol types. Since these non-dust layers are located in lidar signals, in the next step these altitude ranges are removed manually from both the lidar and model profiles. The same procedure is followed for cases in which cirrus clouds are detected in lidar observations.

Additionally, the comparison is carried out only in the free-troposphere region, i.e., above the PBL as determined by lidar observations (Matthias et al., 2004). This choice is related to the fact that the BSC-DREAM8b model calculates only the dust component of the aerosol content and does not provide any information about local and/or different aerosol sources (see Sect. 2.2). Therefore all results reported in the following are related to altitude above the PBL as identified in each single lidar profile. The base of the dust layer 
is forced to be (for model forecasting also) above the PBL, as determined by lidar measurements. Moreover, cases with mixing of dust with other aerosol types in the free troposphere, such as volcanic particles collected for the Eyjafjallajökull eruption in 2010 (see Mona et al., 2012b), are not considered in the present analysis.

An algorithm is implemented for the quantitative identification of layers above the PBL. The main concept is that layer features can be identified through the gradient in the particle backscatter profile as reported in Mona et al. (2006, 2012b). According to this work, the first maximum above the PBL of the first derivative of the aerosol profile is identified as the base of the aerosol layer. We found that the application of this method to the lidar profiles, degraded to the BSCDREAM8b vertical resolution, typically leads to an overestimation of the layer base with respect to the full-resolution lidar profiles, and in some cases to the incapability to define a layer base. To overcome these problems, the first point of positive gradient in the aerosol profile is used to locate the layer base as it indicates that the aerosol content increases after the natural decrease with the altitude toward the PBL top.

On the other hand, the top of the desert dust layer from lidar profiles is identified as the first altitude point above the layer base where aerosol backscatter is lower than a fixed threshold and its derivative is zero. Within the dust layer it is assumed that the backscatter value is higher than the climatological mean evaluated in the $6.5-8.5 \mathrm{~km}$ altitude range, which is typically not affected by significant particle transport (Mona et al., 2006). The layer base and top calculation is performed for each set of lidar simultaneous profiles (for example, a complete data set of three backscatter and two extinction profiles measured at the different wavelengths) on the backscatter profile at the longest available wavelength in order to take advantage of the higher sensitivity to aerosol structures at longer wavelengths. If backscatter profiles are not available for a simultaneous lidar data set, layer base and top are retrieved from the extinction profiles at the longest available wavelength. Furthermore, an internal check is performed with the other wavelengths in order to ensure the accuracy of the layer retrieval.

The determination of base/top from BSC-DREAM8b profiles is done considering that the model provides information only for the desert dust particles: nonzero values in the profiles correspond to dust particles. A minimum extinction value $\left(10^{-4} \mathrm{Mm}^{-1}\right)$ is considered to be a value for the layer identification, taking into account the model uncertainty for low aerosol load. The BSC-DREAM8b dust layer base is calculated as the first point above the PBL (as estimated from lidar data) where the profile or its derivative increases, i.e., situations corresponding to an identifiable increase of optical properties out of the PBL with respect to the typical decrease in the aerosol optical properties with altitude.

Once layer base and top are estimated for both lidar and model profiles, we estimate the center of mass of the dust layer as the mean altitude of the identified layer weighted

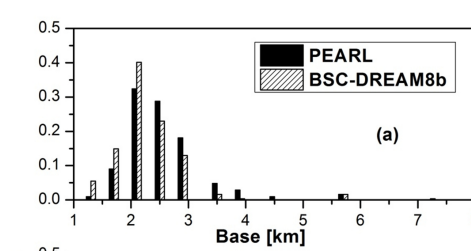

\begin{tabular}{|l|l|}
\hline PEARL mean & $2.5 \pm 0.7 \mathrm{~km}$ \\
\hline BSC-DREAM8b mean & $2.3 \pm 0.6 \mathrm{~km}$ \\
\hline Linear Fit & \\
\hline Linear Correlation & 0.96 \\
\hline Intercept & $-0.1 \pm 0.8 \mathrm{~km}$ \\
\hline Slope & $1.01 \pm 0.04$ \\
\hline \hline PEARL mean & $\begin{array}{l}8.0 \pm 2.7 \mathrm{~km} \\
(6.3 \pm 1.6 \mathrm{~km})\end{array}$ \\
\hline BSC-DREAM8b mean & $\begin{array}{l}10 \pm 4 \mathrm{~km} \\
(6.5 \pm 1.6 \mathrm{~km})\end{array}$ \\
\hline Linear Fit & \\
\hline Linear Correlation & $0.80(0.93)$ \\
\hline Intercept & $2.3 \pm 1.6 \mathrm{~km}$ \\
& $(-0.5 \pm 1.2 \mathrm{~km})$ \\
\hline Slope & $0.50 \pm 0.08$ \\
& $(0.7 \pm 0.1)$ \\
\hline \hline PEARL mean & $3.5 \pm 1.0 \mathrm{~km}$ \\
\hline BSC-DREAM8b mean & $3.8 \pm 1.3 \mathrm{~km}$ \\
\hline Linear Fit & \\
\hline Linear Correlation & 0.98 \\
\hline Intercept & $1.5 \pm 1.1 \mathrm{~km}$ \\
\hline Slope & $0.90 \pm 0.03$ \\
\hline
\end{tabular}

Figure 1. Distribution of the dust layer base (a), top (b) and center of mass (c) as measured by the PEARL lidar and modeled by BSCDREAM8b.

by the altitude-dependent aerosol optical properties (Mona et al., 2006). Assuming the microphysical properties to be homogeneous within the aerosol layer, this quantity indicates the altitude where the most relevant part of the aerosol load is located.

Base, top and center of mass are independently determined for lidar and model profiles case by case. Geometrical features of dust layers as obtained by measurements and the model are compared and discussed in Sect. 4. The linear correlation between lidar and BSC-DREAM8b profiles within the base/top altitude range is calculated as an additional measure of the model's capability to reproduce the aerosol profile in terms of its shape. Finally, the base/top identification method reported above allows for quantitative evaluation of model performances in terms of aerosol extinction forecast.

\section{Results}

\subsection{Layering}

The methodology reported in the previous section is applied to the database of 310 dust cases observed over Potenza in the 2000-2012 period. The main results for dust layer geometrical properties are summarized in Fig. 1 and Table 1.

The dust layer base as estimated from BSC-DREAM $8 b$ profiles is in good agreement with lidar observations: the difference between these two independently estimated values is on average $-0.2 \pm 0.5 \mathrm{~km}$, with absolute differences below $0.2 \mathrm{~km}(0.4 \mathrm{~km})$ for $63 \%(84 \%)$ of the cases, lower than the model resolution at these altitudes. There are, however, a few cases (26 out of 309) for which the base estimated from modeled profiles is at least $1 \mathrm{~km}$ lower than the 
corresponding lidar-measured value. This is related to the difficult discrimination of the local PBL and lofted dust when an intrusion into the PBL also occurred.

Figure 1a reports the distribution of the BSC-DREAM8b and lidar layer base values. The mean BSC-DREAM8b estimation for the dust layer base is $2.3 \pm 0.6 \mathrm{~km}$ and is in agreement within the errors with a lidar-measured mean value of $2.5 \pm 0.7 \mathrm{~km}$. The standard deviations also agree within the errors. This is a further confirmation that the model accounts for a variability in the dust layer base which is in agreement with the observations. The high linear correlation coefficient (0.96) between the distributions reported in Fig. 1a is a quantitative measure of the agreement between observations and the model in terms of layer base. However, larger discrepancies are observed for the dust layer top. The model overestimates the measured top by $2.5 \mathrm{~km}$ on average. The distributions reported in Fig. 1b show that BSC-DREAM8b reports many cases with layer top up to $15 \mathrm{~km}$, while lidar measurements observed dust above $10 \mathrm{~km}$ in only a few cases. This produces a difference of $2 \mathrm{~km}$ in the mean value and an overestimation of its variability of more than $1 \mathrm{~km}$ for the model (see Table 1). The observed difference in layer top reveals that dust particles are often present in the model at very high altitudes, while they are not observed in the lidar profiles. The lidar layer top identification is limited by the signal-tonoise ratio, and therefore lidar observations may underestimate the dust layer top in some cases. However, the model clearly tends to accumulate dust concentrations in the upper levels (dust concentrations observed in altitudes $>10 \mathrm{~km}$ are around $1 \mu \mathrm{g} \mathrm{m}^{-3}$ ), indicating some limitations of the model. In addition to the vertical diffusion (Hong et al., 1996), the tropopause, the boundary for the vertical extension of Saharan dust, is not well reproduced by the model. In general, the numerical models (regional and global) have limitations in reproducing the thermal inversion corresponding to the tropopause (Janjic, 1994). Furthermore, once desert dust achieves these upper levels, the only mechanism to remove dust particles is sedimentation. Consequently, dust has a long residence time associated with it because the removal processes (i.e., wet and dry deposition) are less effective and as a consequence the residence time of dust is longer (more than one week).

The comparison is significantly improved limiting the range of interest below $10 \mathrm{~km}$ (reported in Table 1 in bold face): mean and standard deviation values are in agreement within the model resolution, and the correlation coefficient between the two distributions increased from 0.80 to 0.93 .

An interesting quantity for investigating aerosol layers is the layer center of mass (CoM hereinafter). The dynamical behavior (in time and altitude) of the whole layer can be described by the CoM evolution in the absence of wind shear and under the assumption of homogeneity of aerosol microphysical properties within the layer. This would mean, for instance, that the origin of the dust particles and the traveled path could be investigated by back-trajectory analysis

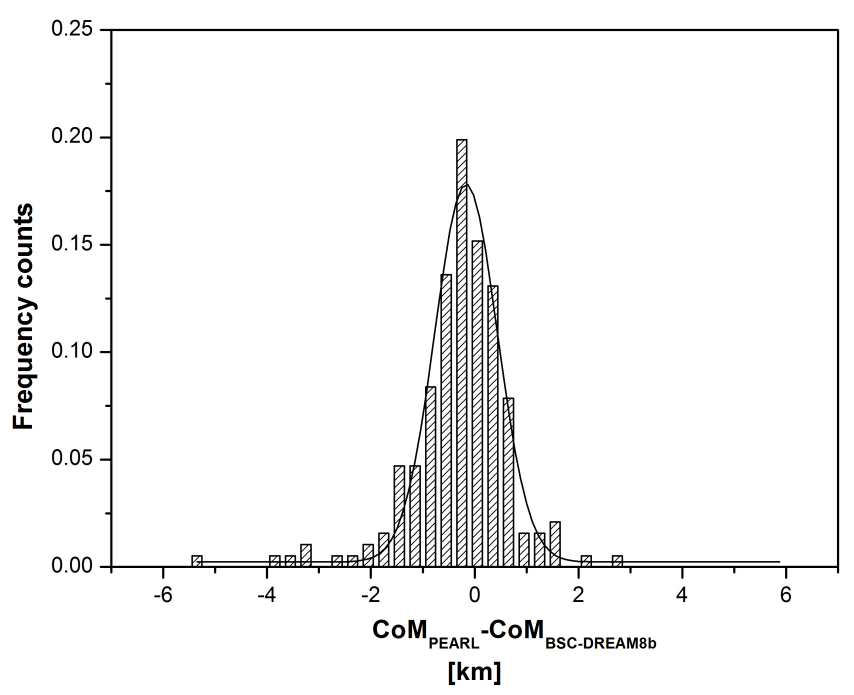

Figure 2. Distribution of the difference of the dust layer CoM as measured by PEARL and evaluated from the BSC-DREAM8b profiles.

of air masses arriving at the CoM altitude in the observational point. The altitude range around the CoM is typically the region of the layer where most of the aerosol particles are located. This altitude is more representative of the whole aerosol layer than the altitude corresponding to the optical property peak value, because this latter could also correspond to an isolated extreme point (Pappalardo et al., 2014). The $\mathrm{CoM}$ as obtained from PEARL and BSC-DREAM8b profiles (see Fig. 2) ranges between 1.5 and $9.5 \mathrm{~km}$ a.s.l., with mean value around $3.5 \mathrm{~km}$ and a variability (estimated as the standard deviation) of about $1 \mathrm{~km}$. The BSC-DREAM $8 \mathrm{~b}$ model on average reproduces the behavior of the identified dust layers' CoM well as resulting from the high correlation (0.98) between the two distributions (see Table 1 and Fig. 1c). We also found very good performance of the model for the estimation of this quantity for each single case. Figure 2 reports the distribution of the difference between the CoM as measured by PEARL and that modeled by BSCDREAM8b. In total, $95 \%$ of the values have a difference of between -2 and $2 \mathrm{~km}$. The model overestimates the CoM by more than $2 \mathrm{~km}$ for seven cases, and the BSC-DREAM $8 \mathrm{~b}$ $\mathrm{CoM}$ is more than $2 \mathrm{~km}$ lower than lidar measured value in only two cases. In particular, a difference of $-5 \mathrm{~km}$ occurred for the 21 August 2000 case: the layer base was around $3.9 \mathrm{~km}$ for both systems whereas the top reached values of up to 10 and $15 \mathrm{~km}$ for lidar and the model, respectively. Moreover the BSC-DREAM8b forecast a layer extending from the base around $3.9 \mathrm{~km}$, with extinction significantly decreased at about $7 \mathrm{~km}$ and a further enhancement of it above $9 \mathrm{~km}$ with a peak at about $13 \mathrm{~km}$. Corresponding PEARL data yielded no aerosol presence over $10 \mathrm{~km}$. Although these cases are sporadic (5\%), a mean difference of $-0.3 \pm 1.0 \mathrm{~km}$ is found, comparable to the model vertical 


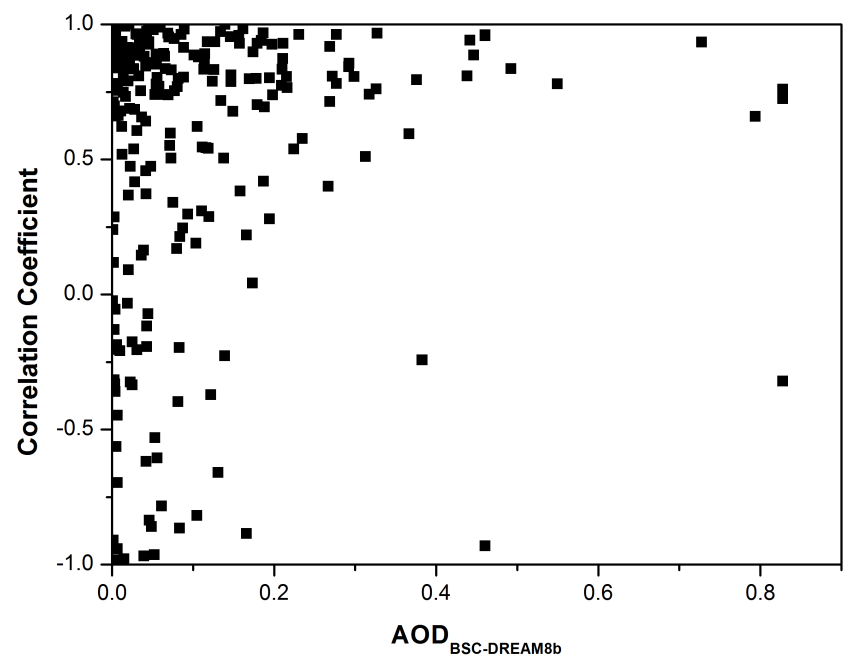

Figure 3. Linear correlation coefficient between PEARL and BSCDREAM8b extinction profiles in the identified dust layer as a function of the model aerosol optical depth (AOD) at $550 \mathrm{~nm}$.

resolution in $1-2 \mathrm{~km}$ altitude range. The differences for the CoM are distributed according to a Gaussian curve (correlation coefficient of 0.986 ) centered at $-0.17 \pm 0.02 \mathrm{~km}$ with a standard deviation of $0.6 \pm 0.02 \mathrm{~km}$.

The linear correlation coefficient, $r_{\text {prof }}$, between measurement and modeled profiles is used as an additional index of BSC-DREAM8b's capability to reproduce the shape of measured dust profiles. $r_{\text {prof }}$ (Fig. 3) is evaluated for the modeled extinction versus the corresponding backscatter profile at $532 \mathrm{~nm}$, as it is the most abundant lidar product available during the 2000-2012 period. The correlation is calculated within the portion of profile identified as desert dust layer from the lidar data. We found that the two profiles are correlated within a significance of $5 \%$ in about $60 \%$ of the cases $\left(r_{\text {prof }}>0.65\right)$. Uncorrelated profiles are mainly related to cases of low aerosol load (see Fig. 3). Of all cases with $r_{\text {prof }}$ lower than 0.6, $70 \%$ correspond to an AOD lower than 0.1 (BSC-DREAM8b estimated). A few outliers (3) are visible in Fig. 3 with AOD in the range of $0.4-0.8$ and which exhibit negative correlation coefficients. From lidar measurements and data analysis, we found that these three cases correspond to highly variable situations, cloud formation at top of the dust layer, and a very sharp non-collocated decrease in both profiles, respectively.

The results reported above are obtained considering the BSC-DREAM8b profile closest in time to the lidar observation time. However the same analysis (not shown for brevity) has been carried out considering the average of BSCDREAM8b profiles over $6 \mathrm{~h}$ around the lidar profile's central time. Results for $6 \mathrm{~h}$ profiles are almost equal to those obtained for the modeled profiles closest in time in terms of mean, standard deviation, correlation values and distributions for all the considered geometrical properties (layer base, top and center of mass) and for the linear correlation between the lidar and modeled profiles.

\subsection{Optical properties}

Aerosol extinction coefficient profiles at $532 \mathrm{~nm}$ measured by the PEARL lidar are available for 58 cases. The PEARL extinction values at $532 \mathrm{~nm}$ are directly compared with the BSC-DREAM8b extinction at $550 \mathrm{~nm}$ because of the wavelength proximity and the low spectral extinction dependence for desert dust as observed at this site (Boselli et al., 2012).

Different altitude ranges show marked differences in terms of model-observations agreement (Fig. 4). The model reproduces the observations distribution at $1-3 \mathrm{~km}$ altitude fairly well: a general decrease with the extinction value is found for the values' occurrence but the correlation coefficient is only 0.81 . Only a few values (15) higher than $5 \mathrm{Mm}^{-1}$ are observed in the $5-7 \mathrm{~km}$ range; this distribution is in fair agreement with that observed (correlation coefficient of 0.94 in the whole range but only 0.6 above $5 \mathrm{Mm}^{-1}$ ). The correlation coefficient between the two distributions for the $3-5 \mathrm{~km}$ altitude range reported in Fig. $4 \mathrm{~b}$ is 0.98 . Moreover, the slope and intercept are consistent within the errors for this altitude range only, with 1 and 0 , respectively. This furthermore demonstrates the capability of the model to reconstruct the dust layers well close to the CoM altitude and in the middle troposphere. This capability is related not only to the dust vertical layering (previous section) but also to the assumptions considered for the extinction calculations (see Sect. 2.2).

The mean extinction profiles and its standard deviation (i.e., its variability in the atmosphere) for the considered cases are reported in Fig. 5. The mean aerosol extinction profiles are calculated for lidar and the model as the average of these cases only within the dust layer. Aerosol extinction values are comparable as an absolute number and, in agreement with results reported in Sect. 3.1, the shape of the profiles is similar above $3 \mathrm{~km}$ altitude. It is worth noting that there is a larger bias between the model and lidar in summer in comparison with spring below $4 \mathrm{~km}$ altitude. This could be partly associated with differences in the dust particle sources that affect Potenza throughout the year. Furthermore, during summer, when photochemical reactions are enhanced, higher extinction values observed at low levels could be associated with aged dust particles and the potential presence of other aerosols (such as fires particles).

Figure 6 shows the comparison in terms of aerosol extinction profiles for desert dust AOD classes. The difference between measured and modeled extinction values is typically higher below $3 \mathrm{~km}$. The correlation between the two profiles increases with AOD, even though the mean difference increases correspondingly. This indicates that the model simulates the profile shape better for intense dust outbreaks (i.e., larger aerosol loads). These cases also correspond to larger discrepancies in terms of extinction values. Again this could be related to enhanced mixing and modification 

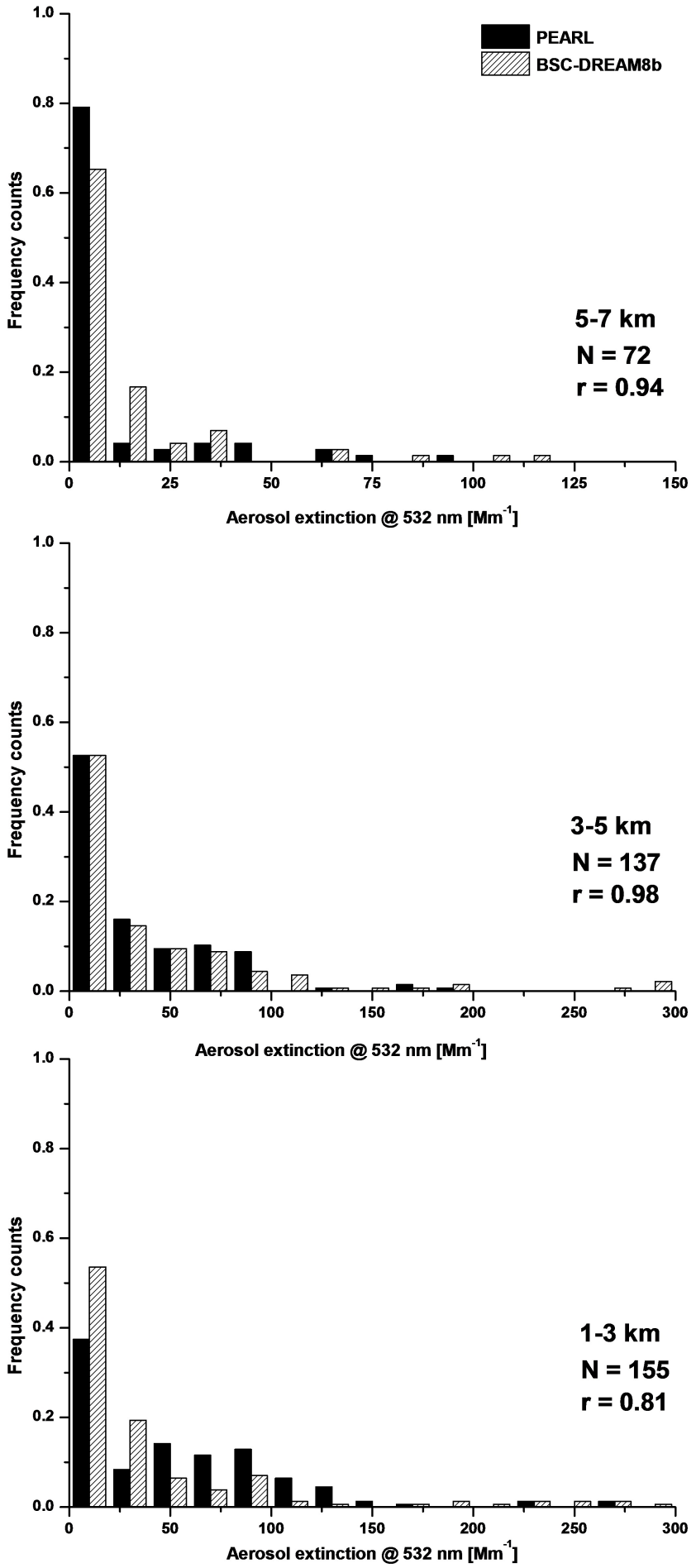

Figure 4. Distributions of aerosol extinction values reported at $532 \mathrm{~nm}$ inside dust layers by PEARL measurements and BSCDREAM8b model. The distributions correspond to three different height classes: $1-3 \mathrm{~km}$ a.s.1. (bottom panel), 3-5 km (middle panel) and $5-7 \mathrm{~km}$ a.s.1. (top panel).
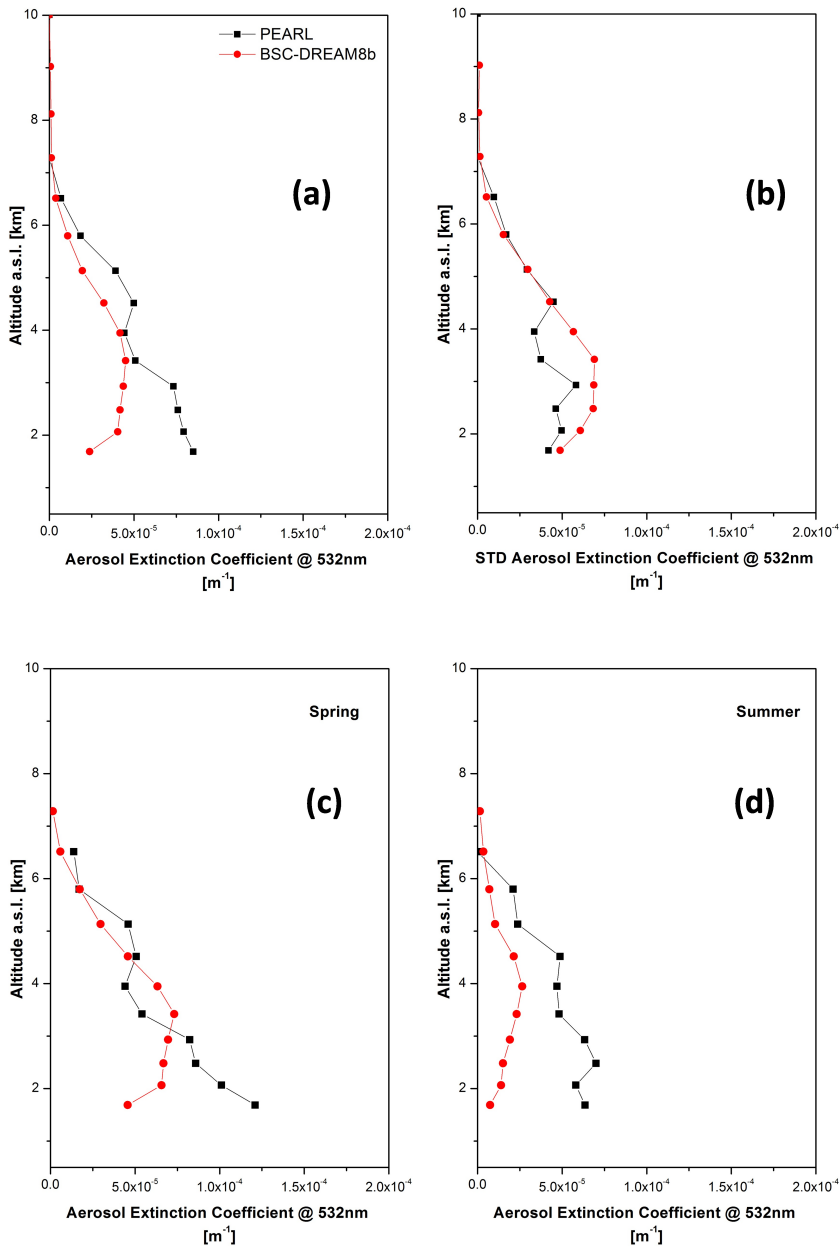

Figure 5. Mean aerosol extinction profiles (a) and related standard deviation profiles (b) calculated for lidar and the model within the identified dust layer. Mean aerosol extinction profiles for spring ((c), 29 profiles) and summer ((d), 21 profiles) cases are reported at the bottom.

processes during the warm seasons, when the highest dust AOD values are observed. However, modification processes are not integrated into the model. Moreover, Saharan dust particles are often mixed with other types of particles (e.g., urban pollution, marine aerosols) particularly for lower altitudes. A study devoted to aerosol typing performed over Europe within the framework of EARLINET (Wandinger et al., 2011) reported that "pure" dust was observed in only $12 \%$ of the dust cases.

Below $3 \mathrm{~km}$, where relative differences are the highest, the measured lidar ratio $(S)$ has, on average, values higher than at upper levels and is also more variable, indicating a mixture of dust with other particles and/or modification processes affecting dust optical properties (e.g., ageing). Sources of the observed differences can be investigated in more detail through intensive properties such as lidar ratio at $532 \mathrm{~nm}$ and the Ångström exponent, $\delta$, at $532 / 355 \mathrm{~nm}$. Figure 7 shows $S$ 


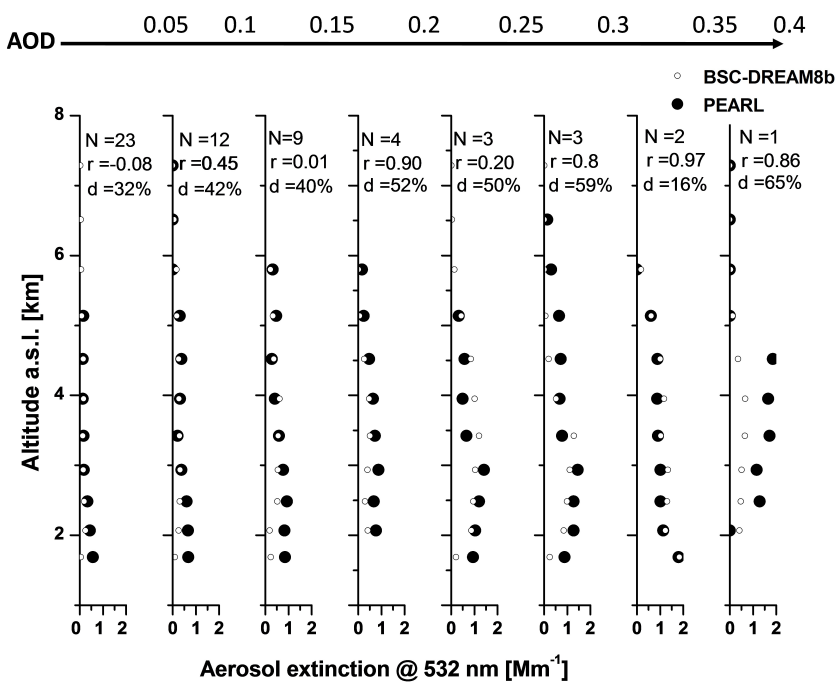

Figure 6. Mean aerosol extinction profiles separated into AOD classes. The number of measurements $(\mathrm{N})$, the linear correlation coefficient among measured and modeled profiles ( $r$ ) and the mean relative difference (d) are reported.

as a function of $\delta$. Relative differences in the extinction values are reported in the $S-\delta$ plane according to a color code. Values are highly scattered and variable in the $20-90 \mathrm{sr}$ and $-0.7-2$ range for $S$ and $\delta$, respectively. Lower lidar ratio values are typically observed for larger $\delta$, indicating that smaller dust particles are less absorbing than larger dust particles.

The mixing relevance in the model-observations comparison is more evident when considering the relative difference classes in Fig. 7. Two classes are almost completely separated in this space. The lowest relative difference class (below $17 \%$ ) is confined to $\delta$ values lower than 0.32 (third quartile), while highest observed differences are mainly related to $\delta$ values higher than 0.39 (first quartile). Differences in the middle range correspond instead to the whole $S-\delta$ range, as demonstrated by the first to third quartile values in Fig. 7. This means that the lowest model-observation differences correspond to an $S$ of and $\delta$ of $60 \pm 13$ sr and $0.1 \pm 0.6$, respectively. These are in agreement with values observed and modeled for pure desert dust (e.g., Ansmann et al., 2003; Papayannis et al., 2008). However, the highest differences (higher than $85 \%)$ are related to larger $\delta$ values $(0.5 \pm 0.6)$, denoting smaller particles. These larger values are in agreement with analogous values observed in southern European stations (Mona et al., 2006; Balis et al., 2004). In synthesis, the level of agreement decreases with increase in mixing/modification processes.

\section{Summary and conclusions}

The database of dust optical properties profiles collected at Potenza (in southern Italy) beginning in 2000 by a multi-

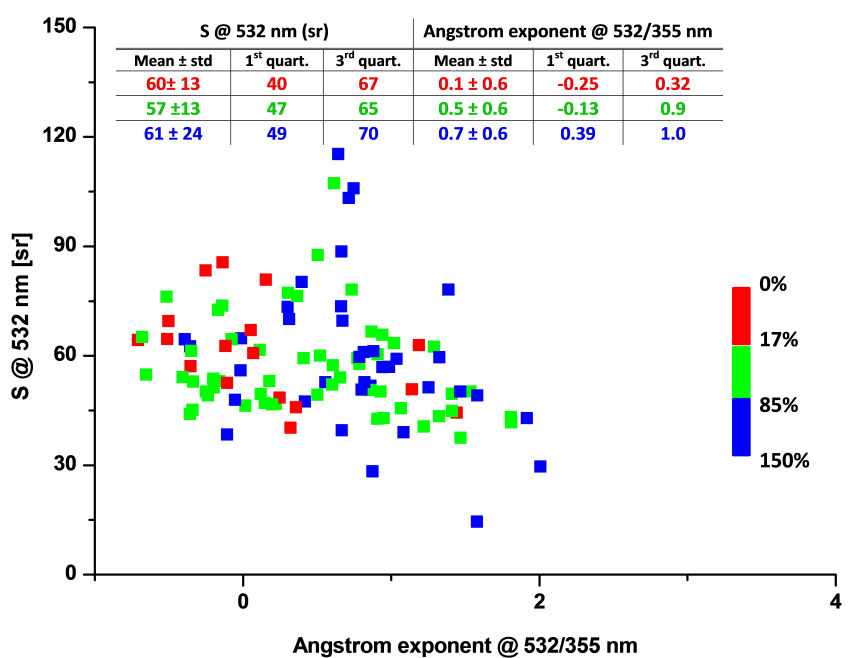

Figure 7. Lidar ratio values measured at $532 \mathrm{~nm}$ inside the dust layer reported as a function of the Angström exponent at $532 / 355 \mathrm{~nm}$. Data are reported following a color code based on relative model-observation difference in aerosol extinction values.

wavelength Raman lidar has been used to evaluate the capability of BSC-DREAM8b to reproduce dust profiles in terms of dust layer geometrical and optical properties. This is, to the best of our knowledge, the first systematic and quantitative evaluation of modeled dust profiles through Raman lidar measurements.

A suitable methodology for taking into account different resolutions (in horizontal, vertical and temporal domains) and external aerosol mixing has been implemented. The comparison approach has been developed paying particular attention to its potential further application to other sites (in particular EARLINET stations) and models.

In general, the BSC-DREAM8b model reconstructs the observed profiles well, even if with some exceptions. The dust layer base is found to be around $2.5 \mathrm{~km}$ a.s.l. and is in agreement with observations: note that we limited our comparison to altitudes above the local PBL, biasing the result to some extent. An observed tendency of the BSCDREAM8b model to overestimate the dust layer top, with values reaching $15 \mathrm{~km}$ in $32 \%$ of the cases, is related to a too long aerosol lifetime in the upper levels of the model resulting from overestimations of the troposphere-stratosphere exchange. Furthermore, the dust layer top is a parameter that is not suitable for use if this approach is applied to other stations/networks because the sensitivity of lidar is a characteristic of each instrument, and therefore the comparison in terms of the layer top cannot be carried out at network level. We found that the dust layer CoM is likely the most suitable geometrical parameter for evaluating the capability of the dust model to reproduce the dust vertical layering. The BSC-DREAM8b model CoM is consistent with a high confidence level (correlation coefficient of 0.986) with respect to lidar measurements. In particular, the case-by-case difference 
is on average $0.3 \pm 1.0 \mathrm{~km}$. The shape of the lidar profile is also reproduced well by BSC-DREAM $8 \mathrm{~b}$ (within $5 \%$ significance) for $60 \%$ of the cases. In $70 \%$ of the cases, uncorrelated profiles are related to an AOD lower than 0.1.

The extinction coefficient as modeled by BSC-DREAM $8 \mathrm{~b}$ underestimates measured values in particular at altitudes lower than $3 \mathrm{~km}$, likely because the model does not consider aerosol internal mixing and modification processes. Differences at the low-altitude range are higher during summer/spring and for higher AOD. However, modelobservation difference in aerosol extinction is higher for smaller particles. Differences below $17 \%$ are typically observed for $S-\delta$ couples around pure dust values, while disagreement increases with the mixing of dust particles with smaller particles.

The study reported in this paper can be considered as a pilot case in which we developed a specific methodology for application to the whole EARLINET network and to other models in the framework of the northern Africa-Middle East-Europe (NA-ME-E) regional center of the World Meteorological Organization's Sand and Dust Storm Warning Assessment and Advisory System Programme (http://sds-was. aemet.es/). Of particular value for enlarging the evaluation to all EARLINET stations is the infrastructural improvement planned within ACTRIS (Aerosols, Clouds, and Trace gases Research InfraStructure Network) for the provision of aerosol layering as a further standard EARLINET product.

For the improvement of the extinction coefficient, it would be important to have information about microphysical aerosol properties. In this sense, novel inversion codes able to provide profiles of microphysical properties by, for example, collocated lidar and sun photometers could provide the missing information for appropriate parameterization (Wagner et al., 2013). Moreover, concentration-to-extinction conversion factor dependence on intensive properties like lidar ratio and depolarization ratio could be investigated through specific measurement campaigns, such as the ACTRIS summer 2012-2013 campaigns, with intensive measurements performed at EARLINET and ACTRIS in situ sites in conjunction with the EMEP and Charmex campaigns.

Acknowledgements. The financial support for EARLINET provided by the European Union under grant RICA 025991 within the framework of the Sixth Framework Programme is gratefully acknowledged. Since 2011 EARLINET has been integrated in the ACTRIS Research Infrastructure Project supported by the European Union Seventh Framework Programme (FP7/2007-2013) under grant agreement no. 262254. J. M. Baldasano and S. Basart acknowledge the "Supercomputación and e-ciencia" project (CSD2007-0050) from the Consolider-Ingenio 2010 program, as well as the Severo Ochoa (SEV-2011-00067) program of the Spanish government. BSC-DREAM8b simulations were performed on the Mare Nostrum supercomputer hosted by the Barcelona Supercomputing Center-Centro Nacional de Supercomputación (BSC-CNS). Ioannis Binietoglou would like to acknowledge funding received from the European Union's Seventh Framework Programme for research, technological development and demonstration under grant agreement no. 289923 - ItaRS. The authors would like to thank the NOAA Air Resources Laboratory (ARL) for the provision of the HYSPLIT back-trajectory analysis, as well as the Norwegian Institute for Air Research for the FLEXPART model. The work performed by M. G. Cava during her bachelor's degree thesis is greatly acknowledged. The authors would like to thank C. Pérez (Department of Applied Physics and Applied Math, Columbia University, New York, USA) for comments on the manuscript.

Edited by: E. Gerasopoulos

\section{References}

Amiridis, V., Kafatos, M., Pérez, C., Kazadzis, S., Gerasopoulos, E., Mamouri, R. E., Papayannis, A., Kokkalis, P., Giannakaki, E., Basart, S., Daglis, I., and Zerefos, C.: The potential of the synergistic use of passive and active remote sensing measurements for the validation of a regional dust model, Ann. Geophys., 27, 3155-3164, doi:10.5194/angeo-27-3155-2009, 2009.

Amiridis, V., Wandinger, U., Marinou, E., Giannakaki, E., Tsekeri, A., Basart, S., Kazadzis, S., Gkikas, A., Taylor, M., Baldasano, J., and Ansmann, A.: Optimizing Saharan dust CALIPSO retrievals, Atmos. Chem. Phys. Discuss., 13, 1474914795, doi:10.5194/acpd-13-14749-2013, 2013.

Ansmann, A., Bösenberg, J., Chaikovsky, A., Comerón, A., Eckhardt, S., Eixmann, R., Freudenthaler, V., Ginoux, P., Komguem, L., Linné, H., Márquez, M. A. L., Matthias, V., Mattis, I., Mitev, V., Müller, D., Music, S., Nickovic, S., Pelon, J., Sauvage, L., Sobolewsky, P., Srivastava, M. K., Stohl, A., Torres, O., Vaughan, G., Wandinger, U., and Wiegner, M.: Longrange transport of Saharan dust to northern Europe: the 1116 October 2001 outbreak observed with EARLINET, J. Geophys. Res., 108, 4783, doi:10.1029/2003JD003757, 2003.

Balis, D. S., Amiridis, V., Nickovic, S., Papayannis, A., and Zerefos, C.: Optical properties of Saharan dust layers as detected by a Raman lidar at Thessaloniki, Greece, Geophys. Res. Lett., 31, L13104, doi:10.1029/2004GL019881, 2004.

Basart, S., Pérez, C., Nickovic, S., Cuevas, E., Schulz, M., and Baldasano, J. M.: Development and evaluation of BSCDREAM8b dust regional model over Northern Africa, the Mediterranean and the Middle East regions, Tellus B, 64, 18539, doi:10.3402/tellusb.v64i0.18539, 2012a.

Basart, S., Pay, M. T., Jorba, O., Pérez, C., Jiménez-Guerrero, P., Schulz, M., and Baldasano, J. M.: Aerosols in the CALIOPE air quality modelling system: evaluation and analysis of PM levels, optical depths and chemical composition over Europe, Atmos. Chem. Phys., 12, 3363-3392, doi:10.5194/acp-12-33632012, 2012b.

Böckmann, C., I., Mironova, I., Müller, D., Scheidenbach, L., and Nessler, R.: Microphysical aerosol parameters from multiwavelength lidar, J. Opt. Soc. Am. A, 22, 518-528, 2005.

Bösenberg, Matthias, J. V., Matthias, V., Amodeo, A., Amoiridis, V., Ansmann, A., Baldasano, J. M., Balin, I., Balis, D., Böckmann, C., Boselli, A., Carlsson, G., Chaikovsky, A., Chourdakis, G., Comerón, A., De Tomasi, F., Eixmann, R., Freudenthaler, V., 
Giehl, H., Grigorov, I., Hågård, A., Iarlori, M., Kirsche, A., Kolarov, G., Komguem, L., Kreipl, S., Kumpf, W., Larchevêque, G., Linné, H., Matthey, R., Mattis, I., Mekler, A., Mironova, I., Mitev, V., Mona, L., Müller, D., Music, S., Nickovic, S., Pandolfi, M., Papayannis, A., Pappalardo, G., Pelon, J., Pérez, C., Perrone, R. M., Persson, R., Resendes, D. P., Rizi, V., Rocadenbosch, F., Rodrigues, A., Sauvage, L., Schneidenbach, L., Schumacher, R., Shcherbakov, V., Simeonov, V., Sobolewski, P., Spinelli, N., Stachlewska, I., Stoyanov, D., Trickl, T., Tsaknakis, G., Vaughan, G., Wandinger, U., Wang, X., Wiegner, M., Zavrtanik, M., and Zerefos, C.: EARLINET: a European Aerosol Research Lidar Network to Establish an Aerosol Climatology, Max-Planck-Institut Report No. 348, Hamburg, Germany, 2003.

Boselli, A., Caggiano, R., Cornacchia, C., Madonna, F., Macchiato, M., Mona, L., Pappalardo, G., and Trippetta, S.: Multi year sun-photometer measurements for aerosol characterization in a Central Mediterranean site, Atmos. Res., 104, 98-110, doi:10.1016/j.atmosres.2011.08.002, 2012.

Boucher, O., D. Randall, P. Artaxo, C. Bretherton, G. Feingold, P. Forster, V.-M. Kerminen, Y. Kondo, H. Liao, U. Lohmann, P. Rasch, S. K. Satheesh, S. Sherwood, B. Stevens, and X. Y. Zhang: Clouds and Aerosols, in: Climate Change 2013: The Physical Science Basis. Contribution of Working Group I to the Fifth Assessment Report of the Intergovernmental Panel on Climate Change, edited by: Stocker, T. F., Qin, D., Plattner, G.-K., Tignor, M., Allen, S. K., Boschung, J., Nauelsm A., Xia, Y., Bex, V., and Midgley, P. M.: Cambridge University Press, Cambridge, United Kingdom and New York, NY, USA, 2013.

D'Almeida, G. A.: Desert aerosol characteristics and effects on climate, in: Palaeoclimatology and Palaeometeorology: Modern and Past Patterns of Global Atmospheric Transport, edited by: Leinen, M. and Sarnthein, M., NATO ASI Series, C, vol. 282, 311-338, 1987.

De Longueville, F., Hountondji, Y.-C., Henry, S., and Ozer, P.: What do we know about effects of desert dust on air quality and human health in West Africa compared to other regions?, Sci. Total. Environ., 409, 1-8, doi:10.1016/j.scitotenv.2010.09.025, 2013.

EARLINET publishing group 2000-2010: EARLINET observations related to Saharan Dust events (2000-2010); World Data Center for Climate (WDCC), http://dx.doi.org/10.1594/WDCC/ EN_VolcanicEruption_2000-2010, 2014.

Fécan, F., Marticorena, B., and Bergametti, G.: Parametrization of the increase of the aeolian erosion threshold wind friction velocity due to soil moisture for arid and semi-arid areas, Ann. Geophys., 17, 149-157, doi:10.1007/s00585-999-0149-7, 1999.

Ferrare, R. A., Melfi, S. H., Whiteman, D. N., Evans, K. D., Poellot, M., and Kaufman, Y. J.: Raman lidar measurements of aerosol extinction and backscattering: 2. Derivation of aerosol real refractive index, single-scattering albedo, and humidification factor using Raman lidar and aircraft size distribution measurements, J. Geophys. Res., 103, 19673-19689, doi:10.1029/98JD01647, 1998.

Ferrare, R. A., Turner, D. D., Brasseur, L. H., Feltz, W. F., Dubovik, O., and Tooman, T. P.: Raman lidar measurements of the aerosol extinction-to-backscatter ratio over the Southern Great Plains, J. Geophys. Res., 106, 20333-20347, doi:10.1029/2000JD000144, 2001.

Ferrare, R. A., Browell, E. V., Hair, J. W., Ismail, S., Turner, D. D., Clayton, M., Butler, C., Brackett, V. G., Fenn, M. A., Notari, A.,
Kooi, S. A., Chin, M., Guibert, S., Schulz, M., Chuang, C., Krol, M., Bauer, S. E., Liu, X., Myhre, G., Seland, Ø., Fillmore, D., Ghan, S., Gong, S., Ginoux, P., and Takemura, T.: The vertical distribution of aerosols: lidar measurements vs. model simulations, in: Reviewed and revised papers presented at the 23rd International Laser Radar Conference, Nara Japan, 2428 July 2006, Chikao Nagasawa and Nobuo Sugimoto Editors, 2006.

Ford, B. and Heald, C. L.: An A-train and model perspective on the vertical distribution of aerosols and $\mathrm{CO}$ in the Northern Hemisphere, J. Geophys. Res., 117, D06211, doi:10.1029/2011JD016977, 2012.

Gallisai, R., Peters, F., Basart, S., and Baldasano, J. M.: Mediterranean basin-wide correlations between Saharan dust deposition and ocean chlorophyll concentration, Biogeosciences Discuss., 9, 8611-8639, doi:10.5194/bgd-9-8611-2012, 2012.

Generoso, S., Bey, I., Labonne, M., and Bréon, F.-M.: Aerosol vertical distribution in dust outflow over the Atlantic: comparisons between GEOS-Chem and Cloud-Aerosol Lidar and Infrared Pathfinder Satellite Observation (CALIPSO), J. Geophys. Res., 113, D24209, doi:10.1029/2008JD010154, 2008.

Giorgi, F.: A particle dry7deposition parameterization scheme for use in tracer transport models, J. Geophys. Res., 91, 9794-9806, 1986.

Gobbi, G. P., Barnaba, F., Ammannato, L.: Estimating the impact of Saharan dust on the year $2001 \mathrm{PM}_{10}$ record of Rome, Atmos. Environ., 41, 261-275, doi:10.1016/j.atmosenv.2006.08.036, 2007.

Griffin D. W.: Atmospheric movement of microorganisms in clouds of desert dust and implications for human health, Clin. Microb. Rev., 20, 3, 459-477, 2007.

Hamza, W., Rizk Enan, M., Al-Hassini, H., Jan-Berend, S., and deBeer, D.: Dust storms over the Arabian Gulf: a possible indicator of climate changes consequences, Aquat. Ecosys. Health Manage., 14, 260-268, 2011.

Hara, Y., Yumimoto, K., Uno, I., Shimizu, A., Sugimoto, N., Liu, Z., and Winker, D. M.: Asian dust outflow in the PBL and free atmosphere retrieved by NASA CALIPSO and an assimilated dust transport model, Atmos. Chem. Phys., 9, 1227-1239, doi:10.5194/acp-9-1227-2009, 2009.

Haustein, K., Pérez, C., Baldasano, J. M., Müller, D., Tesche, M., Schladitz, A., Freudenthaler, V., Heese, B., Esselborn, M., Weinzierl, B., Kandler, K., and von Hoyningen-Huene, W.: Regional dust model performance during SAMUM 2006, Geophys. Res. Lett., 36, L03812, doi:10.1029/2008GL036463, 2009.

Haustein, K., Pérez, C., Baldasano, J. M., Jorba, O., Basart, S., Miller, R. L., Janjic, Z., Black, T., Nickovic, S., Todd, M. C., Washington, R., Müller, D., Tesche, M., Weinzierl, B., Esselborn, M., and Schladitz, A.: Atmospheric dust modeling from meso to global scales with the online NMMB/BSC-Dust model - Part 2: Experimental campaigns in Northern Africa, Atmos. Chem. Phys., 12, 2933-2958, doi:10.5194/acp-12-2933-2012, 2012.

Hong, S.-Y., and Pan, H.-L.: Nonlocal boundary layer vertical diffusion in a medium-range forecast model, Mon. Weather Rev. 124, 2322-2339, 1996.

Janjic, Z. I.: The step-mountain eta coordinate model: further developments of the convection, viscous sublayer and turbulence closure schemes, Mon. Weather Rev., 122, 927-945, 1994. 
Jickells, T. D., An, Z. S., Andersen, K. K., Baker, A. R., Bergametti, G., Brooks, N., Cao, J. J., Boyd, P. W., Duce, R. A., Hunter, K. A., Kawahata, H., Kubilay, N., la Roche, J., S., L. P., Mahowald, N., Prospero, J. M., Ridgwell, A. J., Tegen, I., and Torres, R.: Global iron connections between desert dust, ocean biogeochemistry, and climate, Science, 308, 67-71, 2005.

Jiménez-Guerrero, P., Pérez, C., Jorba, O., and Baldasano, J. M.: Contribution of Saharan dust in an integrated air quality system and its on-line assessment, Geophys. Res. Lett., 35, L03814, doi:10.1029/2007GL031580, 2008.

Johnson, A. and White, N. D.: Ocean Acidification: The Other Climate Change Issue, American Scientist, 102, 1, 60-63, 2014,

Kallos, G., Papadopoulos, A., Katsafados, P., and Nickovic, S.: Transatlantic Saharan dust transport: model simulation and results, J. Geophys. Res., 111, D09204, doi:10.1029/2005JD006207, 2006.

Koepke, P., Hess, M., Schult, I., and Shettle, E. P.: Global aerosol dataset, Report N 243, Max-Plank-Institut für Meteorologie, Hamburg, 44 pp., September 1997.

Koffi, B., Schulz, M., Bréon, F.-M., Griesfeller, I., Winker, D., Balkanski, Y., Bauer, S., Berntsen, T., Chin, M., Collins, W. D., Dentener, F., Diehl, T., Easter, R., Ghan, S., Ginoux, P., Gong, S., Horowitz, L. W., Iversen, T., Kirkevåg, A., Koch, D., Krol, M., Myhre, G., Stier, P., and Takemura, T.: Application of the CALIOP layer product to evaluate the vertical distribution of aerosols estimated by global models: AeroCom phase I results, J. Geophys. Res., 117, D10201, doi:10.1029/2011JD016858, 2012.

Kwon, H. J., Cho, S. H., Chun, Y., Lagarde, F., and Pershagen, G.: Effects of the Asian dust events on daily mortality in Seoul, Korea, Environ. Res., 90, 1-5, 2002.

Liu, Z., Omar, A., Vaughan, M., Hair, J., Kittaka, C., Hu, Y. X., Powell, K., Trepte, C., Winker, D., Hostetler, C., Ferrare, R., and Pierce, R.: CALIPSO lidar observations of the optical properties of Saharan dust: a case study of long-range transport, J. Geophys. Res., 113, D07207, doi:10.1029/2007JD008878, 2008.

Lovett, R. : African dust keeps Amazon blooming, Nature, doi:10.1038/news.2010.396, 2010.

Madonna, F., Amodeo, A., Boselli, A., Cornacchia, C., Cuomo, V., D’Amico, G., Giunta, A., Mona, L., and Pappalardo, G.: CIAO: the CNR-IMAA advanced observatory for atmospheric research, Atmos. Meas. Tech., 4, 1191-1208, doi:10.5194/amt-4-11912011, 2011.

Matthias, V., Balis, D., Bösenberg, J., Eixmann, R., Iarlori, M., Komguem, L., Mattis, I., Papayannis, A., Pappalardo, G., Perrone, M. R., and and Wang, X.: The vertical aerosol distribution over Europe: statistical analysis of Raman lidar data from 10 EARLINET stations, J. Geophys. Res., 109, D18201, doi:10.1029/2004JD004638, 2004.

Mishchenko, M. I., Travis, L. D., and Lacis, A. A.: Scattering, Absorption, and Emission of Light by Small Particles, Cambridge University Press, Cambridge UK, 2002.

Mona, L., Amodeo, A., Pandolfi, M., and Pappalardo, G.: Saharan dust intrusions in the Mediterranean area: three years of Raman lidar measurements, J. Geophys. Res., 111, D16203, doi:10.1029/2005JD006569, 2006.

Mona, L., Pappalardo, G., Amodeo, A., D’Amico, G., Madonna, F., Boselli, A., Giunta, A., Russo, F., and Cuomo, V.: One year of CNR-IMAA multi-wavelength Raman lidar measurements in coincidence with CALIPSO overpasses: Level 1 products comparison, Atmos. Chem. Phys., 9, 7213-7228, doi:10.5194/acp-97213-2009, 2009.

Mona, L., Liu, Z., Mueller, D., Omar, A., Papayannis, A., Pappalardo, G., Sugimoto, N., and Vaughan, M.: Lidar measurements for desert dust characterization: an overview, Advances in Meteorology, 2012, 356265, doi:10.1155/2012/356265, 2012a.

Mona, L., Amodeo, A., D’Amico, G., Giunta, A., Madonna, F., and Pappalardo, G.: Multi-wavelength Raman lidar observations of the Eyjafjallajökull volcanic cloud over Potenza, southern Italy, Atmos. Chem. Phys., 12, 2229-2244, doi:10.5194/acp-12-22292012, 2012b.

Müller, D., Franke, K., Ansmann, A., Althausen, D., and Wagner, F.: Indo-Asian pollution during INDOEX: microphysical particle properties and single-scattering albedo inferred from multiwavelength lidar observations, J. Geophys. Res., 108, 4600, doi:10.1029/2003JD003538, 2003.

Müller, D., Mattis, I., Ansmann, A., Wehner, B., Althausen, D., Wandinger, U., and Dubovik, O.: Closure study on optical and microphysical properties of an urban/arctic haze plume observed with Raman lidar and Sun photometer, J. Geophys. Res., 109, D13206, doi:10.1029/2003JD004200, 2004.

Nickovic, S., Kallos, G., Papadopoulos, A., and Kakaliagou, O.: A model for prediction of desert dust cycle in the atmosphere, J. Geophys. Res., 106, 18113-18130, doi:10.1029/2000JD900794, 2001.

Osterloh, L., Pérez, C., Böhme, D., Baldasano, J. M., Böckmann, C., Schneidenbach, L., and Vicente, D.: Software for the retrieval of aerosol microphysical properties from lidar data in the framework of EARLINET-ASOS, Comput. Phys. Commun., 180, 2095-2102, doi:10.1016/j.cpc.2009.06.011, 2009.

Papayannis, A., Amiridis, V., Mona, L., Tsaknakis, G., Balis, Bösenberg J., Chaikovski, A., De Tomasi, F., Grigorov, I., Mattis, I., Mitev, V., Müller D., Nickovic, S., Pérez C., Pietruczuk, A., Pisani, G., Ravetta, F., Rizi, V., Sicard, M., Trickl, T., Wiegner, M., Gerding, M., D'Amico, G., and Pappalardo, G.: Systematic lidar observations of aerosol optical properties during Saharan dust intrusions over Europe, in the frame of EARLINET (2000-2002): statistical analysis and results, J. Geophys. Res., 113, D10204, doi:10.1029/2007JD009028, 2008.

Pappalardo, G., Amodeo, A., Apituley, A., Comeron, A., Freudenthaler, V., Linné, H., Ansmann, A., Bösenberg, J., D’Amico, G., Mattis, I., Mona, L., Wandinger, U., Amiridis, V., AladosArboledas, L., Nicolae, D., and Wiegner, M.: EARLINET: towards an advanced sustainable European aerosol lidar network, Atmos. Meas. Tech., 7, 2389-2409, doi:10.5194/amt-7-23892014, 2014.

Pay, M. T., Piot, M., Jorba, O., Gassó, S., Gonçalves, M., Basart, S., Dabdub, D., Jiménez-Guerrero, P., and Baldasano, J. M.: A full year evaluation of the CALIOPE-EU air quality modeling system over Europe for 2004, Atmos. Environ., 44, 3322-3342, doi:10.1016/j.atmosenv.2010.05.040, 2010.

Pay, M. T., Jiménez-Guerrero, P., Jorba, O., Basart, S., Querol, X., Pandolfi, M., and Baldasano, J. M.: Spatio-temporal variability of concentrations and speciation of particulate matter across Spain in the CALIOPE modeling system, Atmos. Environ., 46, 376396, 2012. 
Pérez, C., Nickovic, S., Baldasano, J. M., Sicard, M., Rocadenbosch, F., and Cachorro, V. E.: A long Saharan dust event over the western Mediterranean: lidar, sun photometer observations, and regional dust modeling, J. Geophys. Res., 111, D15214, doi:10.1029/2005JD006579, 2006a.

Pérez, C., Nickovic, S., Pejanovic, G., Baldasano, J. M., and Ozsoy, E.: Interactive dust-radiation modeling: a step to improve weather forecasts, J. Geophys. Res., 11, D16206, doi:10.1029/2005JD006717, 2006b.

Pérez García-Pando, C., Stanton, M., Diggle, P., Trzaska, S., Miller, R. L., Perlwitz, J. P., Baldasano, J. M., Cuevas, E., Ceccato, P., Yaka, P., and Thomson, M.: Soil dust aerosols and wind as predictors of seasonal meningitis incidence in Niger, Environ. Health Perspect, 2014,

Perez, L., Medina-Ramon, M., Kunzli, N., Alastuey, A., Pey, J., Perez, N., Garcia, R., Tobias, A., Querol, X., Sunyer, J.: Size fractionated particulate matter, vehicle traffic, and case-specific daily mortality in Barcelona (Spain), Environ. Sci. Technol., 43, 4707-4714, doi:10.1021/es8031488, 2009.

Querol, X., Pey, J., Pandolfi, M., Alastuey, A., Cusack, M., Perez, N., Moreno, T., Viana, M., Mihalopoulos, N., Kallos, G., and Kleanthous, S.: African dust contributions to mean ambient $\mathrm{PM}_{10}$ mass-levels across the Mediterranean Basin, Atmos. Environ., 43, 4266-4277, ISI:000269095400003, 2009.

Sawamura, P., Vernier, J. P., Barnes, J. E., Berkoff, T. A., Welton, E. J., Alados-Arboledas, L., Navas-Guzmán, F., Pappalardo, G., Mona, L., Madonna, F., Lange, D., Sicard, M., Godin-Beekmann, S., Payen, G., Wang, Z., Hu, S., Tripathi, S. N., Cordoba-Jabonero, C., and Hoff, R. M.: Stratospheric AOD after the 2011 eruption of Nabro volcano measured by lidars over the Northern Hemisphere, Environ. Res. Lett., 7, 034013, doi:10.1088/1748-9326/7/3/034013, 2012.

Schuster, G. L., Vaughan, M., MacDonnell, D., Su, W., Winker, D., Dubovik, O., Lapyonok, T., and Trepte, C.: Comparison of CALIPSO aerosol optical depth retrievals to AERONET measurements, and a climatology for the lidar ratio of dust, Atmos. Chem. Phys., 12, 7431-7452, doi:10.5194/acp-12-7431-2012, 2012.

Shao, Y., Raupach, M. R., and Findlater, P. A.: Effect of saltation bombardment on the entrainment of dust by wind, J. Geophys. Res., 98, 12719-12726, 1993.
Stohl, A.: Computation, accuracy and applications of trajectories a review and bibliography, Atmos. Environ., 32, 947-966, 1998.

Stohl, A. and Thomson, D. J.: A density correction for Lagrangian particle dispersion models, Bound.-Lay. Meteorol., 90, 155-167, 1999.

Tegen, I. and Lacis, A. A.: Modeling of particle size distribution and its influence on the radiative properties of mineral dust aerosol, J. Geophys. Res., 101, 19237-19244, doi:10.1029/95JD03610, 1996.

Todd, M. C., Bou Karam, D., Cavazos, C., Bouet, C., Heinold, B., Baldasano, J. M., Cautenet, G., Koren, I., Perez, C., Solmon, F., Tegen, I., Tulet, P., Washington, R., and Zakey, A.: Quantifying uncertainty in estimates of mineral dust flux: an intercomparison of model performance over the Bodélé Depression, northern Chad, J. Geophys. Res., 113, D24107, doi:10.1029/2008JD010476, 2008.

Veselovskii, I., Dubovik, O., Kolgotin, A., Korenskiy, M., Whiteman, D. N., Allakhverdiev, K., and Huseyinoglu, F.: Linear estimation of particle bulk parameters from multi-wavelength lidar measurements, Atmos. Meas. Tech., 5, 1135-1145, doi:10.5194/amt-5-1135-2012, 2012.

Wagner, J., Ansmann, A., Wandinger, U., Seifert, P., Schwarz, A., Tesche, M., Chaikovsky, A., and Dubovik, O.: Evaluation of the Lidar/Radiometer Inversion Code (LIRIC) to determine microphysical properties of volcanic and desert dust, Atmos. Meas. Tech., 6, 1707-1724, doi:10.5194/amt-6-1707-2013, 2013.

Wandinger, U., Hiebsch, A., Mattis, I., Pappalardo, G., Mona, L., and Madonna, F.: Aerosols and Clouds: Long-Term Database from Spaceborne Lidar Measurements, Final report, ESTEC, Noordwijk, The Netherlands, 15 pp., 2011.

WHO, Meningococcal Meningitis Fact Sheet: World Health Organization, Geneva, Switzerland, 2003.

Winker, D. M., Vaughan, M. A., Omar, A., Hu, Y., Powell, K. A., Liu, Z., Hunt, W. H., and Young, S. A.: Overview of the CALIPSO mission and CALIOP data processing algorithms, J. Atmos. Ocean. Tech., 26, 2310-2323, doi:10.1175/2009JTECHA1281.1, 2009.

WMO Secretariat: WMO Sand and Dust Storm Warning Advisory and Assessment System (SDSWAS) - Science and Implementation Plan 2011-2015, 13 March 2011, Research Department, Atmospheric Research and Environment Branch, World Meteorological Organization, Geneva, Switzerland, 18 pp., 2011. 